\title{
Lifestyle changes in coronary heart disease-Effects of cardiac rehabilitation programs with focus on intensity, duration and content-A systematic review
}

\author{
Camilla Strid $^{1 *}$, Hans Lingfors ${ }^{2}$, Bengt Fridlund ${ }^{3}$, Jan Mårtensson $^{3}$ \\ ${ }^{1}$ Department of Medicine, Höglandssjukhuset, Eksjö, Sweden \\ ${ }^{2}$ Health Centre of Habo and Development Unit for Primary Health Care, Jönköping, Sweden \\ ${ }^{3}$ Department of Nursing, School of Health Sciences, Jönköping, Sweden \\ Email: ${ }^{*}$ camilla.strid@telia.com
}

Received 21 September 2012; revised 6 November 2012; accepted 2 December 2012

\begin{abstract}
Background: Although coronary heart disease (CHD) is the most common cause of death worldwide the literature shows a wide variation in the arrangement of cardiac rehabilitation and achieved lifestyle changes. Aim: The purpose of this study was to evaluate the effects of intensity (number of patient follow-ups), duration (length of intervention) and content in cardiac rehabilitation programs (CRP) regarding lifestyle changes in patients with CHD. Method: A systematic literature review of articles published in the databases PubMed and CINAHL between 1990 and 2007 was conducted. This resulted in $\mathbf{1 1 2 0}$ hits of which $\mathbf{2 5}$ articles finally met the set criteria for inclusion. Results: The majority of significant positive results on lifestyle factors were shown among the studies describing high intensity and long duration. Included studies showed a wide variation in content, but four different interventions (informative content, educational content, practical content, behavioral and self care-oriented content) emerged. The group of studies which contained all four interventions focused on most lifestyle factors and achieved the most significant positive results. Conclusion: This systematic literature review shows that CRP should include high intensity, long duration and an intervention content covering information, knowledge, practical training, self care-activity and behavior changes in order to achieve effect on all four lifestyle factors of diet, physical activity and exercise, smoking and stress. Lifestyle changes can be reached in less lifestyle factors, with a longer duration and a variation of intensity of contacts but in combining with an informative and educational content with an additional content of a practical nature or self activity.
\end{abstract}

\footnotetext{
*Corresponding author.
}

Keywords: Coronary Heart Disease; Secondary Prevention; Cardiac Rehabilitation; Lifestyle; Intensity; Duration; Content; Systematic Review

\section{INTRODUCTION}

Coronary heart disease (CHD) is the most common cause of death, followed by stroke [1]. The care of patients with acute myocardial infarction has been improved by new drugs, rapid treatment in the acute phase and the widespread introduction of routine coronary angiography, often followed by percutaneous coronary intervention (PCI) or coronary artery bypass surgery (CABG). But still major emphasis is needed in the control of risk factors [2-4].

Well-known lifestyle risk factors underlie a significant proportion of coronary heart disease in the world. Biological risk markers such as high cholesterol, high blood pressure, diabetes and abdominal obesity, together with lifestyle factors such as smoking, low consumption of fruit and vegetables, low physical activity and psychological stress explain up to $90 \%$ of all myocardial infarcts regardless of sex, age or geographical location [5]. Both in studies as well as in national and international guidelines there are today well established cardiac rehabilitation (CR) measures that have been shown to reduce risk factors, such as medication and lifestyle related interventions. These interventions lead to improved quality of life and reduced risk for disease recurrences and death [4,6-10]. As early as the 1990's, Ornish demonstrated significant lifestyle changes and reduction of coronary artery stenoses in patients with CHD who participated in an intensive lifestyle program including physical exercise, diet and stress management [8]. These lifestyle changes were often maintained as long as five years, at which time further reductions of coronary artery stenoses could be measured [11]. The Ornish study had a major 
impact on the importance of multiple lifestyle changes in patients with CHD. Despite knowledge of risk factors relevant to the onset of CHD and the importance of secondary preventive interventions, recommended medical targets and adherence to lifestyle changes are not achieved to the extent that can be expected $[3,12]$.

CR in patients with CHD is defined as the sum of all initiated activities required to positively affect the underlying causes of CHD in order to achieve the best possible physical, mental and social ability [13]. Prevention of CHD aims to reduce morbidity and mortality. The current guidelines recommend multiple interventions where each patient's risk profile is screened. A high grade of evidence and good scientific support exists for lifestyle changes and the measures frequently taken in CR. These include healthy diet, physical activity and exercise, smoking cessation and psychological intervention as well as stress management [4,14-17].

The range of cardiac rehabilitation programs (CRP) is divergent due to differences in methods and organization. Information with counseling and group instruction including physical education and targeted contributions for smoking cessation, diet changes and stress management are part of many interventions in Sweden, as in other parts of the western world [3,6]. Evaluation of the impact of lifestyle changes in this type of intervention has shown that secondary prevention actions need to be further developed and improved to have impact on all risk factors [18]. A meta-analysis of 63 randomized trials studied the effect of multiple CR with or without a physical training component. The results showed that a CR with a wide variation had a positive effect on lifestyle factors, the use of proven effective medical treatment, functional status and quality of life. Recurrence of myocardial infarction decreased by $17 \%$ during a 12 month follow-up period. Mortality varied from 15\% $47 \%$, dependent on the follow-up duration [6].

Knowledge of how many patient contacts CR should include (intensity), how long the contact should last (duration) and what content the $\mathrm{CR}$ should consist of to reach the greatest possible adherence to lifestyle changes in patients with CHD has not been identified. This systematic literature review aimed to evaluate the effects of intensity, duration and content of CRP regarding lifestyle changes in patients with CHD.

\section{METHOD}

Systematic literature review was used as a method. Articles were chosen in two steps with regard to primary and secondary inclusion criteria (Table 1). The endpoints of the study were the impact on the most studied lifestyle factors in CR; dietary change, physical activity and exercise, smoking cessation and stress management. As guidelines recommend multiple interventions on all risk factors [4], focus on at least two of these lifestyle factors was required for inclusion.

Three concepts were used for classification of the material: intensity, which concerned the number of patient contacts $(\leq 20$ or $>20)$; duration of action, relating to the intervention length ( $\leq 3$ months or $>3$ months) and content, relating to intervention content. The content consisted of: An informative and educational content aimed to increase patients' knowledge about CHD and their understanding of lifestyle factors relevant to the onset and relapse of CHD (often multi-factorial, team-based lessons); a more practical content aimed to teach through practical training and experience in groups (e.g., physical

Table 1. Compilation of inclusion criteria.

\begin{tabular}{|c|c|c|}
\hline Inclusion criteria & $\begin{array}{l}\text { Primary } \\
\text { inclusion }\end{array}$ & $\begin{array}{l}\text { Secondary } \\
\text { inclusion }\end{array}$ \\
\hline Articles in PubMed and CINAHL published between 1990 and 2007. & $\mathrm{X}$ & \\
\hline Empirical articles, written in English, published in a peer-reviewed journal. & $X$ & \\
\hline Middle aged patients ( $\leq 70$ years) & $\mathrm{X}$ & \\
\hline Patients with CHD. & $\mathrm{X}$ & \\
\hline Interventions for male and/or female. & $\mathrm{X}$ & \\
\hline Study the effects of CRP. & $\mathrm{X}$ & \\
\hline $\begin{array}{l}\text { Contained of at least one of the following factors or closely associated factor in each group: } \\
\text { Secondary preventive intervention: Secondary prevention, rehabilitation, follow-up care, prevention and } \\
\text { control, patient education; } \\
\text { Risk factors: Motor activity, exercise, physical fitness, diet, food habits, stress/psychological/rehabilitation/ } \\
\text { prevention and control, tobacco use cessation, smoking cessation, risk factors; } \\
\text { Lifestyle change: Lifestyle, self care, health behavior, risk reduction behavior, behavior therapy, patient } \\
\text { compliance/adherence. }\end{array}$ & $\mathrm{X}$ & \\
\hline $\begin{array}{l}\text { Focus on at least two of the lifestyle factors; dietary change, physical activity and exercise, smoking } \\
\text { cessation and stress management. }\end{array}$ & & $\mathrm{X}$ \\
\hline Articles assessed to be good or fair based on the use of examination protocols. & & $\mathrm{X}$ \\
\hline
\end{tabular}


training, cooking); a behavioral content with emphasis on modification of lifestyle behaviors (e.g., smoking cessation, stress management); and a self-care activity content in home environment (e.g., diary, skill training, home training program) with associated monitoring and evaluation.

Medical Subject Headings (MeSH) was applied. The validity of the key words was verified by finding studies in the subject area from well-established researchers. The systematic literature search covered articles in PubMed and CINAHL published between 1990 and 2007, starting from Ornish's groundbreaking results in 1990 [8]. Initial search keywords in PubMed and CINAHL were myocardial ischemia, prevention and control, rehabilitation, patient education, secondary prevention, motor activity, exercise, physical fitness, diet, food habits, stress, smoking cessation, tobacco use cessation, lifestyle, health behavior, risk reduction behavior, behavior therapy, patient compliance, self care and risk factors. The primary inclusion of articles was established through a review of abstracts based on the criteria described above. The first 200 abstracts were reviewed by all authors to ensure there was agreement in inclusion and exclusion criteria, which was the case. The same search strategy was used in both databases with small modifications to reach similar hits.

A total of 1120 abstracts were identified (967 in PubMed and 153 in CINAHL). The first author reviewed all 1120 abstracts of which 88 abstracts (76 in PubMed and 12 in CINAHL) were consistent with the inclusion criteria. Five abstracts were found in both PubMed and CI-
NAHL, giving a final discovery of 83 abstracts. The remaining 1032 abstracts were excluded (Figure 1).

Eight abstracts could not be retrieved and were also excluded. Remaining articles $(n=75)$ were examined based on secondary inclusion criteria and on a modified qualitative and quantitative review protocol according to Willman \& Stoltz [19]. Based on these examination protocols, the quality of the studies were rated on a three grade scale; good, fair or poor. Criteria for these assessments were made subjectively, but with support from criteria according to Forsberg \& Wengström [20]. Articles deemed to be good (fulfilled $>80 \%$ of the criteria) or fair (fulfilled $>60 \%$ of the criteria) were included, while those deemed poor were excluded. To achieve inter-rater reliability, the authors studied and analyzed the first 13 articles, first separately and then together, to determine inclusion or exclusion. Concordance in assessment was found in all 13 articles. A total of 25 articles met the criteria for inclusion, all with quantitative approach.

\section{RESULTS}

\subsection{Description of Studies Design}

The studies $(\mathrm{n}=25)$, grouped in a matrix (Table 2$)$, included 6723 patients (4918 men and 1805 women). The average age ranged from 51 - 62 years. Two studies presented results only for men [21,22]. In one study [23] nearly half of the patients were women, while in the remaining studies $20 \%$ - 35\% were women. The studies came from Scandinavia $(n=9)$, rest of Europe $(n=8)$, North America $(n=7)$ and Australia $(n=1)$. Of the in-

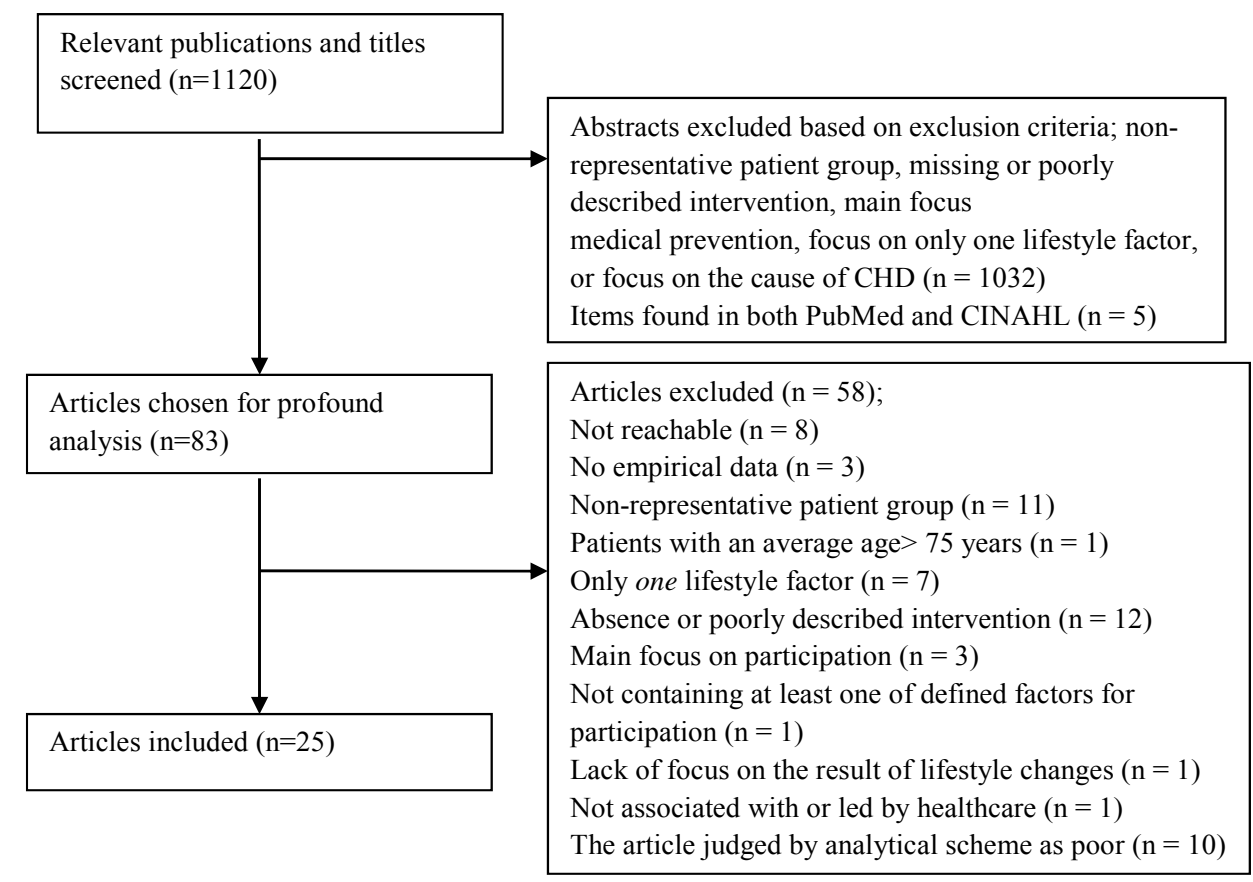

Figure 1. Schedule of search results, inclusion and exclusion of selected abstracts and articles. 
Table 2. Compilation of results of included studies.

\begin{tabular}{|c|c|c|c|c|c|c|c|c|c|c|}
\hline \multirow{2}{*}{$\begin{array}{l}\text { Study title, year, } \\
\text { reference no }\end{array}$} & \multicolumn{2}{|c|}{ Intensity } & \multicolumn{2}{|c|}{ Duration } & \multicolumn{4}{|c|}{ Content } & \multirow[b]{2}{*}{ Endpoint } & \multirow{2}{*}{$\begin{array}{l}\text { Significant } \\
\text { improvement }\end{array}$} \\
\hline & $\begin{array}{c}\leq \mathbf{2 0} \\
\text { contacts }\end{array}$ & $\begin{array}{c}>20 \\
\text { contacts }\end{array}$ & $\leq 3$ months & $>\mathbf{3}$ months & 1 & 2 & 3 & 4 & & \\
\hline Lisspers, et al. 1998. [40] & & $\mathrm{X}$ & & $\mathrm{X}$ & $\mathrm{X}$ & $\mathrm{X}$ & $\mathrm{X}$ & $\mathrm{X}$ & $\begin{array}{l}\text { Diet } \\
\text { Physical training } \\
\text { Stress } \\
\text { Smoking }\end{array}$ & $\begin{array}{l}\text { Yes } \\
\text { Yes } \\
\text { Yes } \\
\text { Yes }\end{array}$ \\
\hline Lisspers, et al. 2005. [42] & & $X$ & & $\mathrm{X}$ & $\mathrm{X}$ & $\mathrm{X}$ & $\mathrm{X}$ & $\mathrm{X}$ & $\begin{array}{l}\text { Diet } \\
\text { Physical training } \\
\text { Stress } \\
\text { Smoking }\end{array}$ & $\begin{array}{l}\text { Yes } \\
\text { Yes } \\
\text { Yes } \\
\text { Yes }\end{array}$ \\
\hline Lisspers, et al. 1999. [41] & & $\mathrm{X}$ & & $\mathrm{X}$ & $\mathrm{X}$ & $X$ & $\mathrm{X}$ & $\mathrm{X}$ & $\begin{array}{l}\text { Diet } \\
\text { Physical training } \\
\text { Smoking } \\
\text { Stress }\end{array}$ & $\begin{array}{l}\text { Yes } \\
\text { Yes } \\
\text { Yes } \\
\text { No }\end{array}$ \\
\hline $\begin{array}{l}\text { Hofman-Bang, et al. } \\
\text { 1999. [38] }\end{array}$ & & $X$ & & $\mathrm{X}$ & $\mathrm{X}$ & $X$ & $\mathrm{X}$ & $\mathrm{X}$ & $\begin{array}{l}\text { Diet } \\
\text { Physical training } \\
\text { Smoking } \\
\text { Stress }\end{array}$ & $\begin{array}{l}\text { Yes } \\
\text { Yes } \\
\text { Yes } \\
\text { No }\end{array}$ \\
\hline $\begin{array}{l}\text { Alm-Roijer, et al. } 2004 . \\
\text { [24] }\end{array}$ & $\mathrm{X}$ & & $\mathrm{X}$ & & $\mathrm{X}$ & $\mathrm{X}$ & & & $\begin{array}{l}\text { Diet } \\
\text { Physical training } \\
\text { Stress } \\
\text { Smoking }\end{array}$ & $\begin{array}{l}\text { Yes } \\
\text { Yes } \\
\text { Yes } \\
\text { No }\end{array}$ \\
\hline Sundin, et al. 2003. [22] & & $\mathrm{X}$ & & $\mathrm{X}$ & $\mathrm{X}$ & $X$ & $\mathrm{X}$ & $\mathrm{X}$ & $\begin{array}{l}\text { Diet } \\
\text { Physical training } \\
\text { Smoking } \\
\text { Stress }\end{array}$ & $\begin{array}{l}\text { Yes } \\
\text { Yes } \\
\text { No } \\
\text { No }\end{array}$ \\
\hline Ornish, et al. 1990. [8] & & $\mathrm{X}$ & & $\mathrm{X}$ & $\mathrm{X}$ & $X$ & $X$ & $\mathrm{X}$ & $\begin{array}{l}\text { Diet } \\
\text { Physical Training } \\
\text { Stress }\end{array}$ & $\begin{array}{l}\text { Yes } \\
\text { Yes } \\
\text { Yes }\end{array}$ \\
\hline Ornish, et al. 1998. [11] & & $\mathrm{X}$ & & $\mathrm{X}$ & $\mathrm{X}$ & $X$ & $\mathrm{X}$ & $\mathrm{X}$ & $\begin{array}{l}\text { Diet } \\
\text { Physical Training } \\
\text { Stress }\end{array}$ & $\begin{array}{l}\text { Yes } \\
\text { Yes } \\
\text { Yes }\end{array}$ \\
\hline $\begin{array}{l}\text { Van Elderen \& } \\
\text { Dusseldorp. 2001. [34] a }\end{array}$ & $\mathrm{X}$ & $\mathrm{X}$ & $\mathrm{X}$ & $\mathrm{X}$ & $\mathrm{X}$ & $\mathrm{X}$ & $\mathrm{X}$ & & $\begin{array}{l}\text { Diet } \\
\text { Physical Training } \\
\text { Smoking }\end{array}$ & $\begin{array}{l}\text { Yes/Yes } \\
\text { Yes/No } \\
\text { Yes/Yes }\end{array}$ \\
\hline $\begin{array}{l}\text { Vestfold Heartcare Study } \\
\text { Group. 2003. [33] }\end{array}$ & $\mathrm{X}$ & & & $\mathrm{X}$ & $\mathrm{X}$ & $\mathrm{X}$ & $\mathrm{X}$ & & $\begin{array}{l}\text { Diet } \\
\text { Physical Training } \\
\text { Smoking }\end{array}$ & $\begin{array}{l}\text { Yes } \\
\text { Yes } \\
\text { Yes }\end{array}$ \\
\hline Wallner, et al. 1999. [32] & $\mathrm{X}$ & & & $\mathrm{X}$ & $\mathrm{X}$ & $X$ & & $\mathrm{X}$ & $\begin{array}{l}\text { Diet } \\
\text { Physical Training } \\
\text { Smoking }\end{array}$ & $\begin{array}{l}\text { Yes } \\
\text { Yes } \\
\text { No }\end{array}$ \\
\hline Campell, et al. 1998. [23] & $\mathrm{X}$ & & & $\mathrm{X}$ & $\mathrm{X}$ & & & & $\begin{array}{l}\text { Diet } \\
\text { Physical Training } \\
\text { Smoking }\end{array}$ & $\begin{array}{l}\text { Yes } \\
\text { Yes } \\
\text { No }\end{array}$ \\
\hline Murchie, et al. 2003. [28] & $\mathrm{X}$ & & & $\mathrm{X}$ & $\mathrm{X}$ & & & & $\begin{array}{l}\text { Diet } \\
\text { Physical Training } \\
\text { Smoking }\end{array}$ & $\begin{array}{l}\text { Yes/Yes } \\
\text { Yes/No } \\
\text { No/No }\end{array}$ \\
\hline Carlsson. 1997. [36] & & $\mathrm{X}$ & $\mathrm{X}$ & & $\mathrm{X}$ & $X$ & & & $\begin{array}{l}\text { Diet } \\
\text { Physical Training } \\
\text { Smoking }\end{array}$ & $\begin{array}{l}\text { Yes } \\
\text { No } \\
\text { No }\end{array}$ \\
\hline $\begin{array}{l}\text { Oldenburg, et al. } 1995 . \\
\text { [31] }\end{array}$ & $\mathrm{X}$ & & & $\mathrm{X}$ & $\mathrm{X}$ & $\mathrm{X}$ & $\mathrm{X}$ & $\mathrm{X}$ & $\begin{array}{l}\text { Diet } \\
\text { Physical Training } \\
\text { Smoking }\end{array}$ & $\begin{array}{l}\text { No } \\
\text { No } \\
\text { No }\end{array}$ \\
\hline Reid, et al. 2005. [43] d & & $\mathrm{X}$ & $\mathrm{X}$ & $X$ & $\mathrm{X}$ & $X$ & $X$ & & $\begin{array}{l}\text { Diet } \\
\text { Physical Training } \\
\text { Smoking }\end{array}$ & $\begin{array}{l}\text { No } \\
\text { No } \\
\text { No }\end{array}$ \\
\hline
\end{tabular}




\section{Continued}

\begin{tabular}{|c|c|c|c|c|c|c|c|c|c|c|}
\hline Lear, et al. 2006. [39] & & $\mathrm{X}$ & & $\mathrm{X}$ & $\mathrm{X}$ & $\mathrm{X}$ & & $X$ & $\begin{array}{l}\text { Diet } \\
\text { Physical Training } \\
\text { Smoking }\end{array}$ & $\begin{array}{l}\text { No } \\
\text { No } \\
\text { No }\end{array}$ \\
\hline Lear, et al. 2003. [27] & $\mathrm{X}$ & & & $\mathrm{X}$ & & $\mathrm{X}$ & & $\mathrm{X}$ & $\begin{array}{l}\text { Diet } \\
\text { Physical Training } \\
\text { Smoking }\end{array}$ & $\begin{array}{l}\text { No } \\
\text { No }\end{array}$ \\
\hline Hansen, et al. 2006. [26] & $\mathrm{X}$ & & & $X$ & $\mathrm{X}$ & & & $\mathrm{X}$ & $\begin{array}{l}\text { Physical Training } \\
\text { Smoking }\end{array}$ & $\begin{array}{l}\text { Yes } \\
\text { Yes }\end{array}$ \\
\hline Mittag, et al. 2006. [30] & $\mathrm{X}$ & & & $X$ & $X$ & & & & $\begin{array}{l}\text { Physical Training } \\
\text { Smoking }\end{array}$ & $\begin{array}{l}\text { Yes }(\mathrm{M}) / \mathrm{No}(\mathrm{F}) \\
\text { Yes }\end{array}$ \\
\hline Aldana, et al. 2003. [35] d & & $\mathrm{X}$ & $\mathrm{X}$ & $\mathrm{X}$ & $\mathrm{X}$ & $\mathrm{X}$ & $\mathrm{X}$ & & $\begin{array}{l}\text { Diet } \\
\text { Physical Training }\end{array}$ & $\begin{array}{l}\text { Yes } \\
\text { No }\end{array}$ \\
\hline $\begin{array}{l}\text { Brüggeman, et al. } 2007 . \\
\text { [21] a }\end{array}$ & $\mathrm{X}$ & $\mathrm{X}$ & $\mathrm{X}$ & & $\mathrm{X}$ & $\mathrm{X}$ & $\mathrm{X}$ & & $\begin{array}{l}\text { Diet } \\
\text { Physical Training }\end{array}$ & $\begin{array}{l}\text { No } \\
\text { No }\end{array}$ \\
\hline Gordon, et al. 2002. [37] & & $\mathrm{X}$ & $\mathrm{X}$ & & $\mathrm{X}$ & $\mathrm{X}$ & & $\mathrm{X}$ & $\begin{array}{l}\text { Diet } \\
\text { Smoking }\end{array}$ & $\begin{array}{l}\text { No } \\
\text { No }\end{array}$ \\
\hline Fox, et al. 2001. [25] & $\mathrm{X}$ & & $\mathrm{X}$ & & $\mathrm{X}$ & $\mathrm{X}$ & & & $\begin{array}{l}\text { Diet } \\
\text { Smoking }\end{array}$ & $\begin{array}{l}\text { No } \\
\text { No }\end{array}$ \\
\hline $\begin{array}{l}\text { Nordmann, et al. } 2001 . \\
\text { [29] }\end{array}$ & $\mathrm{X}$ & & & $\mathrm{X}$ & $\mathrm{X}$ & & & & $\begin{array}{l}\text { Diet } \\
\text { Smoking }\end{array}$ & $\begin{array}{l}\text { No } \\
\text { No }\end{array}$ \\
\hline
\end{tabular}

$1=$ informational and educational content; $2=$ practical content; $3=$ behavioral content; $4=$ self activity-oriented content. $\mathrm{F}=$ female, $\mathrm{M}=$ male. ${ }^{*}=$ indicate results from two different measurement occasions in the included studies with different significant improvements in lifestyle factors. $a=$ indicate comparison with different intervention groups regarding to intensity and/or duration in the included studies.

cluded studies, 20 were randomized controlled studies and five were non-randomized, controlled trials. In general, the randomized studies compared an intervention consisting of some form of counseling, education, training and behavior modification to their normal form of follow-up, which was often scantily described. The effects of the CRPs were generally positive and there was no study in which the control group had a better effect. The included studies consisted of advice and education in some combination concerning healthy diet, physical activity and exercise, weight loss, smoking cessation, stress management, blood pressure and diabetes control and adherence to medical treatment. The patients had a diagnosis of CHD based on angina pectoris, myocardial infarction, coronary artery bypass surgery (CABG) or percutaneous coronary intervention (PCI).

The interventions' intensity, duration and content varied in the studies as did the result of endpoint adherence to lifestyle changes in diet modification, increased physical activity/exercise, smoking cessation and stress management (Table 2).

\subsection{Intensity}

In 11 of 25 studies [23-33] the intensity was $\leq 20$ patient contacts (Table 2). In four of these interventions, the intensity was described as evenly distributed throughout the CRP intervention period $[23,28-30]$. In the other seven studies, a higher intensity of the intervention approach was described in the initial post-cardiac contact, with diminishing intensity described for the remaining follow-up period [24-27,31-33]. Significant improvements were reached to $100 \%$ in three of the lower-intensity studies $[26,30,33]$ in which the intervention was directed against two or three lifestyle factors. Three studies found effects on two of the expected three lifestyle factors $(67 \%)[23,28,32]$. Four studies with lower intensity did not demonstrate any effects, despite interventions in two or three lifestyle factors $[25,27,29,31]$.

In one study, a combination of three interventions was tested. The intensity was lower in two and higher in one of the interventions. Significant improvements of the lifestyle factors were reached in all three interventions after three months but only in two interventions after 12 months [34]. Two interventions were tested in one study, one of which was with lower intensity and the second with higher intensity, without being able to demonstrate any significant improvements on any of the interventions [21].

In 12 studies $[8,11,22,35-43]$ the intensity was $>20$ patient contacts (Table 2). Seven of these interventions were based on patients initially being housed for four weeks at an intervention unit for participation in a major lifestyle and behavioral change program $[8,11,22,38$, 40-42]. In these studies, intervention focused on at least three lifestyle factors of which stress was included in all. Significant improvements were reached in four $(100 \%)$ lifestyle factors in two studies [40,42], and in three endpoints $(100 \%)$ in two other studies. [8,11]. Effects in three of the expected four lifestyle factors $(75 \%)$ were found in two studies $[38,41]$. Of the remaining studies, lifestyle changes were reached to $50 \%$ in two studies, of 
which impact on two of the expected four lifestyle factors was described in one study [22] and on one of the expected two lifestyle factors in the other [35]. In one study, effect was reached in only one of the expected three lifestyle factors (33\%) [36]. Three studies could not demonstrate any intervention-related effects $[37,39,43]$.

\subsection{Duration}

CRP $\leq 3$ months was described in five studies $[21,24,25$, 36,37] (Table 2). Significant improvement were demonstrated on three of the four expected lifestyle factors (75\%) in one study [24] and in another study on one of the expected three lifestyle factors (33\%) [36]. The other three studies did not demonstrate any lifestyle-related improvements [21,25,37].

In three studies interventions were tested against each other, one with a shorter duration and one with a longer duration $[34,35,43]$. In one study three different interventions were tested, one with a shorter duration and two with a longer duration. Significant improvements were demonstrated on three lifestyle factors after three months in all interventions (100\%) and after 12 months in only two lifestyle factors (67\%) [34]. One study demonstrated significant improvements on one of the expected two lifestyle factors $(50 \%)$ from an intervention of shorter duration [35]. One study included an intervention with 33 patient contacts in 3 months and another intervention with 33 patient contacts in 12 months without being able to show any lifestyle impact in the expected three endpoints [43].

CRP $>3$ months was described in 17 of 25 studies [8, 11,22,23,26-33,38-42] (Table 2). Three long- term interventions were among those studies, one of which lasted a total of two years [33] and the other two for four years $[28,39]$. In seven studies with longer duration, lifestyle changes were reached to $100 \%[8,11,26,30,33,40,42]$ (Table 2). These studies differed from each other regarding the number of endpoint measures.

Interventions related to all lifestyle factors were made in two of these studies [40,42], against three lifestyle factors in three studies $[8,11,33]$ and against two lifestyle factors in two of these studies [26,30]. Of the remaining studies of longer duration, interventions were made against all lifestyle factors with significant improvements on three $(75 \%)$ in two studies $[38,41]$; against two to three endpoints with a goal accomplishment in terms of lifestyle factors of $50 \%-67 \%$ in four studies $[22,23,28$, 32]; and against two to three lifestyle factors without any demonstrated significant improvements in four studies $[27,29,31,39]$.

\subsection{Content}

The studies included different combinations of the de- scribed intervention content. Limited content, with CRP essentially based on information and education in CHD and lifestyle, were described in four studies [23,28-30] (Table 2). Endpoints were reached in one of these studies with intervention in two lifestyle factors (100\%) [30]. In two studies, significant improvements were reached in two of the expected three lifestyle factors $(67 \%)[23,28]$. One study could not demonstrate any improvements [29].

In five studies, CRP was based on an informative and educational content, supplemented with one other element [24-27,36] (Table 2). Supplement with a practical content was described in three of these interventions [24, $25,36]$, supplement with own activity in one study [26] and a combination of practical content with own activity in one study [27]. In one study, lifestyle changes were reached in every endpoint the interventions were directed against [26]. Significant improvements were found on three of the four lifestyle factors (75\%) in one study [24] and in another study on one lifestyle factor (33\%) [36]. Two studies could not demonstrate any lifestyle related improvements $[25,27]$.

Three studies compared interventions with different content among the groups $[21,34,37]$ (Table 2). Supplementing an informative and educational content and practical content with a third content of self activity was studied in one of the interventions without proving any lifestyle-related improvements [37]. This was done also in one of three interventions in another study [34]. This study also had an intervention with only one practical content through group physical training. Significant improvements were found in all three interventions after three months on three lifestyle factors $(100 \%)$ and after 12 months in two lifestyle factors (67\%) [34]. Two different interventions were described in yet another study, one of which contained an informative and educational content combined with a practical content and the other with the addition of a behavioral content with intervenetion against two lifestyle factors. None were able to demonstrate any lifestyle related improvement [21].

In five of the studies CRP was based on three interventions in various combinations $[32,33,35,39,43]$ (Table 2). The informative and educational content was combined with both a practical content and a behavioral content in three studies $[33,35,43]$. One of these studies described two interventions that were compared against a control group where one of the groups was given the above-described contents and the other group a more practical content in the form of physical training and self-directed training activity [35]. Two studies combined information and education with a practical content and a self-care activity [32,39]. None of the studies with three different interventions demonstrated any significant improvement on all four lifestyle factors, but one study 
showed effects on each of the three lifestyle factors studied $(100 \%)$ [33]. One study showed significant improvements in two of three lifestyle factors (67\%) [32] another study showed significant improvement in one of the study's two interventions in one of two expected lifestyle factors (50\%) [35]. The remaining two studies did not show any lifestyle-related significant improvements $[39,43]$.

Of the included studies, eight contained all four described intervention contents [8,11,22,31,38,40-42] (Table 2). Four studies $[8,11,40,42]$ found significant improvements on all lifestyle factors the interventions were directed towards $(100 \%)$ with the difference that the intervention was directed to three lifestyle factors in two of the studies $[8,11]$ and to all four lifestyle factors in two other studies [40,42]. Significant improvements were found in three of the expected four lifestyle factors $(75 \%)$ in two studies $[38,41]$. One study demonstrated significant improvements on two of the four expected lifestyle factors (50\%) [22] One study could not demonstrate any lifestyle-related significant improvement [31].

\section{DISCUSSION}

This is the first systematic literature review with the aim to evaluate the effects of intensity, duration and content in CRP regarding lifestyle changes in patients with CHD. From the perspective of intensity, it appeared that the most significant positive results for lifestyle changes were made among the studies that described a higher intensity. Studies with most endpoints and most significant positive results were found among studies of longer duration. Included studies showed a wide variation in content, but four different intervention components emerged. The studies with the most endpoints and most significant positive results were found in the group that included all four intervention components.

Several studies described a higher intensity during the early period of CRP with diminishing intensity during the remaining time. The initial period after an acute cardiac event is also the time when the need for secondary preventive efforts both in medical treatment and lifestyle-related efforts is the greatest, with greater possibility to influence the risk factors. Studies with an even distribution of the contacts were few and generally showed poorer performance on endpoints. Studies with lower intensity showed significant improvement on fewer lifestyle factors, but the interventions were also targeted towards fewer endpoints and had a more limited content. Although there is a high grade of evidence for intervention in dietary change, physical activity and exercise, smoking cessation and stress management, several studies have chosen to study only one or two of these interventions. International and national guidelines support multifactorial intervention including the above lifestyle factors $[4,10]$. Among studies with higher intensity, seven studies stood out with higher initial intensity, based on an inpatient, residential stay at an intervention unit during the first four weeks following inclusion for participation in a major lifestyle and behavioral change program directed toward all lifestyle factors. The expected outcomes, and thus interventions toward these lifestyle factors, in these studies were greater and more targeted, with $100 \%$ significant improvements in four of these studies [8,11,40,42]. Cobb et al. [44], in a systematic review, studied the effect of interventions on risk factors for CHD in eight included studies between 1999 and 2004. To achieve change in risk profile, their recommendation was frequent and regular follow-up to observe progress, provide time for questions and to give encouragement in person or by telephone. In our literature review, 100\% goal accomplishments in all expected endpoints were seen in three of the studies with lower intensity [26,33-34] and in four studies with higher intensity $[8,11,40,42]$. However, due to differences in the number of expected endpoints, the goal accomplishment rate was considered greater in the groups with higher intensity, where the endpoint was significant improvements on all four lifestyle factors. This reinforces the importance of defining the intervention goals and adjusting the intensity and the contents of the intervention. Patients with highest risk of developing CHD are the patients who benefit most from preventive measures [4]. For identification of these patients, the primary preventive risk assessment instrument "Systematic Coronary Risk Evaluation (SCORE)", can be used. It indicates the 10 year risk to die from stroke or CHD and is based on risk factors such as age, sex, smoking, systolic blood pressure and total cholesterol [4]. There is no corresponding risk assessment instrument in the case of secondary prevention. Risk factors such as physical inactivity and exercise, poor diet and negative psychosocial factors must be added to risk assessment to achieve an overall assessment of the patient's total risk.

There is a great difference in duration among the included studies. Half of the interventions of shorter duration showed no significant improvement on lifestyle factors [21,25,37,43]. Reid et al. [43] is the only included study where the effects of various intervention durations were compared. No significant improvement were detected to duration, but in both groups positive improvement were seen on cardiovascular and pulmonary function, physical activity, LDL cholesterol, quality of life and depressive symptoms. Among interventions with longer duration, seven studies out of seventeen showed $100 \%$ significant improvements in the expected lifestyle factors $[8,11,26,30,33,40,42]$. The studies that showed significant improvement on all four lifestyle factors; dietary change, physical activity and exercise, smoking 
cessation and stress management, were among the studies with long duration $[40,42]$. These studies had an abundant content, which affected the results. A richer content requires probably a longer duration. A study that intended to study the effects of CRP with or without a physical training component showed that mortality decreased with longer intervention duration regardless of the intervention combination [6]. Lifestyle changes require difficult and prolonged work and it is the responsibility of the health care professionals to help patients to succeed in their work by providing required knowledge, support and long-term follow-up [45]. Resource availability and different health care professionals are a limitation for long-term follow-up even though they seem to be important for success. The lifestyle changes that have been initiated must be maintained, and work on risk factor reduction must continue when care professionals change. This requires good collaboration among care professionals and adherence to guidelines.

The contents of the included studies were grouped into four different intervention contents with different purposes and in various combinations. Information and education about CHD were included in all studies and were seen as the most basic content and were used as the only content in four studies [23,28-30]. The results from only information and education are very limited. This suggests that CRP must consist of more content components if the intervention shall have its intended effect. Most commonly, the studies applied an informative and educational content combined with an additional content of a practical nature or self activity. All four content interventions were applied in eight of the included studies $[8,11$, 22,31,38,40-42]. Here again, there were studies with interventions aimed at most lifestyle factors. Six of the eight studies that reached $100 \%$ of the endpoints included behavior oriented content. The reductions of stress are shown mainly in studies with a behavioral content. The majority of included studies lacked a behavior oriented intervention, reflecting the fact that behavior oriented interventions require a different qualification of the personnel involved, as well as more contacts for a longer time. There is also contradictory evidence as to what extent stress management affects mortality in CHD [10]. A group-based psychosocial intervention program for women with $\mathrm{CHD}$ has shown to improve survival [46]. Significant improvements were seen on all lifestyle factors the interventions were directed against in four of the studies with all the content components $[8,11,40,42]$. Ornish et al. [8,11], with intensive residential centered intervention was among these studies. This study also showed that the greater adherence to CRP participants achieved, the greater were the effects on lifestyle factors, with greater reduction of coronary artery stenoses. This intervention was in many aspects extreme and was applied to a small population, but the objective of their study was to study what was possible and not what was applicable, i.e. show what lifestyle changes could actually achieve. This type of intervention is more costly for the healthcare system and also more demanding for the patient involved, with the conesquence that several people chose not to participate. The risk is that some patient groups are not reached by lifestyle changes, such as women, elderly people, low income groups and ethnic minorities. Less than $50 \%$ of patients with CHD participate in CRP [47]. Adherence to lifestyle changes is complex, regardless of intensity, duration and content. The pedagogical tools that affect behavior change play a major role and may explain the variation in results of different CRP interventions.

This systematic literature review has some limitations. The grouping of intervention content and duration of action emerged from the analysis of included studies and were considered by the authors to be an acceptable classification given how this activity works. Grouping of the number of patient contacts of $\leq 20$ and $>20$ times were more difficult to determine because CRP is usually made up of so many interventions with different intensity. Whilst the analysis of the included studies showed that this was a reasonable classification which facilitated a comparison of included studies it may be considered as a limitation of the study. Several of the included studies had a limited description of both the intervention as well as of the standard follow-up that the control group received. This limits the opportunity for comparisons and conclusions. Even though drop outs were a factor assessed in the examination protocol, some of the studies had a vague explanation of internal drop outs. This reduces the possibilities to present the effects of adherence. Evaluation of the intervention effects were often in the form of self-reports by questionnaires to patients on lifestyle changes such as diet and exercise. There is always a risk that patients overestimate their lifestyle changes [12]. The absence of included qualitative studies means that we cannot reproduce the patients' experiences of participation in CRP. Keyword combination limited the selection of articles which may have led to some relevant articles not being identified. However, the articles that were included met the criteria for inclusion and quality. Even the restrictive inclusion criteria may have led to exclusion of some relevant articles but these criteria made it possible to separate articles for the purpose of this study [48].

\section{CONCLUSION}

This systematic review shows that the intensity should be high, the duration long, and the intervention content should include information, knowledge, practical training, self activity and behavior modification to achieve effects 
on all four lifestyle factors; dietary changes, physical activity and exercise, smoking cessation and stress management. Lifestyle changes can be reached in less lifestyle factors (diet, physical activity and exercise, smoking), with a longer duration and a variation of intensity of contacts but combining with an informative and educational content with an additional content of a practical nature or self activity. The number of risk factors varies in patients with CHD. To be resource effective, the patients with highest risk factor profile, and therefore with the greatest risk of disease recurrence, must be identified and subject to the most comprehensive intervention. It is therefore important to establish routines for screening risk profiles in patients with CHD. It is also important to continuously evaluate the interventions regarding their effects on lifestyle factors and, based on this, to improve CRP for patients with CHD. More studies are needed in the future where CRP is evaluated with a focus on intensity, duration and content. In addition, more studies are needed focusing on screening effects in relation to specific actions and their effects on lifestyle factors, diet, exercise, smoking and stress.

\section{REFERENCES}

[1] WHO (2004) The global burden of disease. http://www.who.int/healthinfo/global_burden_disease/20 04 report update/en/index.html

[2] The National Board of Health and Welfare (2004) The National Board of Health and Welfare guidelines for cardiac care 2004. Socialstyrelsen, Stockholm.

[3] Wallentin, L., Stenestrand, U., Lindahl, B., Tydén, P., Hambreus, K., James, S. and Lagerqvist, B. (2007) Annual report RIKS-HIA, SEPHIA, SCAAR. The National Board of Health and Welfare, Stockholm.

[4] Graham, I., Atar, D., Borch-Johnsen, K., Boysen, G., Burell, G., Cifkova, R., et al. (2007) European society of cardiology. European guidelines on cardiovascular disease prevention in clinical practice: Executive summary. European Journal of Cardiovascular Prevention and Rehabilitation, 14, 1-40. doi:10.1097/01.hjr.0000277983.23934.c9

[5] Yusuf, S., Hawken, S., Ounpuu, S., Dans, T., Avezum, A., Lanas, F., et al. (2004) Effect of potentially modifiable risk factors associated with myocardial infarction in 52 countries (the INTERHEART study): Case-control study. Lancet, 364, 937-952. doi:10.1016/S0140-6736(04)17018-9

[6] Clark, A.M., Hartling, L., Vandermeer, B. and McAlister, F. (2005) Meta-analysis: Secondary prevention programs for patients with coronary artery disease. Annals of Internal Medicine, 143, 659-672.

[7] De Backar, G., Ambosioni, E., Borch-Johnsen, K., Brotons C., Cifkova R., Dallongeville J., et al. (2003) European guidelines on cardiovascular diseases prevention in clinical practice. Third joint task force of European and other societies on cardiovascular disease prevention in clinical practice. European Heart Journal, 24, 1601-1610. doi:10.1016/S0195-668X(03)00347-6

[8] Ornish, D., Brown, S., Scherwitz, L., Billings, J., Armstrong, W., Ports, T., et al. (1990) Can lifestyle changes reverse coronary heart disease? The lifestyle heart trial. Lancet, 336, 129-133. doi:10.1016/0140-6736(90)91656-U

[9] Shephard, R.J. and Balady, G.J. (1999) Exercise as cardiovascular therapy. Circulation, 99, 963-972. doi:10.1161/01.CIR.99.7.963

[10] The National Board of Health and Welfare (2008) Coronary heart disease - scientific basis for national Guidelines for cardiac care. Socialstyrelsen, Stockholm.

[11] Ornish, D., Scherwitz, L.W., Billings, J.H., Gould, L., Merritt, T., Sparler, S., et al. (1998) Intensive lifestyle changes for reversal of coronary heart disease. JAM: The Journal of the American Medical Association, 280, 2001-2008.

[12] Kotseva, K., Wood, D., De Backer, G., De Bacquer, D., Pyörälä, K. and Keil, K. (2009) Eurospire III: A survey on the lifestyle, riskfactors and use of cardioprotective drug therapies in coronary patients from 22 European countries. European Journal of Cardiovascular Prevention and Rehabilitation, 16, 121-137. doi:10.1097/HJR.0b013e3283294b1d

[13] Wood, D., De Backer, G., Faegerman, O., Kjekshus, J., Wedel, H., Berg, K., et al. (1998) Members of task force. Prevention of coronary heart disease in clinical practice. Recommendation of the second joint task force of European and other societies on coronary prevention. European Heart Journal, 19, 1434-1503. doi:10.1053/euhj.1998.1243

[14] Linden, W., Stossel, C. and Maurice, J. (1996) Psychosocial interventions for patients with coronary artery disease: A meta-analysis. Archives of Internal Medicine, 156, 745-752. doi:10.1001/archinte.1996.00440070065008

[15] De Lorgerli, M., Salen, P., Martini, J.L., Monjaud, I., Delay, J. and Mamelle, N. (1999) Mediterranean diet, traditional risk factors, and the rate of cardiovascular complications after myocardial infarction: Final report of the Lyon diet heart study. Circulation, 99, 779-785. doi:10.1161/01.CIR.99.6.779

[16] Stead, L.F. and Lancaster, T. (2005) Group behaviour therapy programmes for smoking cessation. Cochrane Database of Systematic Reviews, 149, 656-672.

[17] Taylor, R., Brown, A., Ebrahim, S., Jolliffe, J., Noorani, H., Rees, K., et al. (2004) Exercise-based rehabilitation for patients with coronary heart disease: Systematic review and meta analysis of randomised controlled trials. American Journal of Medicine, 116, 682-692. doi:10.1016/j.amjmed.2004.01.009

[18] Bellman, C., Hambreus, K., Lindbäck, J. and Lindahl, B. (2009) Achievement of secondary preventive goals after myocardial infarction: A comparison between participants and non-participants in a routine patient education programme in Sweden. European Journal of Cardiovascular Nursing, 24, 362-368.

[19] Willman, A., Stoltz, P. and Bahtsevani, C. (2006) Evidencebased nursing; a bridge between research and clinical practice. Studentlitteratur, Lund. 
[20] Forsberg, C. and Wengström, Y. (2003) To conduct a systematic literature review. Natur och Kultur, Stockholm.

[21] Brüggemann, J., Poels, B., Oosterwijk, M., Van der Schans, C., Postema, K. and van Veldhuisen, D.Q. (2007) A randomised controlled trial of cardiac rehabilitation after revascularisation. International Journal of Cardiology, 19, 59-64. doi:10.1016/j.ijcard.2006.07.047

[22] Sundin, Ö., Lisspers, J., Hofman-Bang, C., Nygren, Å., Rydén, L. and Öhman, A. (2003) Comparing multifactoral lifestyle interventions and stress management in coronary risk reduction. Internal Journal of Behavioural Medicine, 10, 191-204. doi:10.1207/S15327558IJBM1003 01

[23] Campell, N.C., Ritchie, L.D., Thain, J., Deans, H.G., Rawles, J.M. and Squair, J.L. (1998) Secondary prevention in coronary heart disease: A randomised trial of nurse led clinics in primary care. Heart, 80, 447-452.

[24] Alm-Roijer, C., Stagmo, M., Udén, G. and Erhardt, L. (2004) Better knowledge improves adherence to lifestyle changes and medication in patients with coronary heart disease. European Journal of Cardiovascular Nursing, 3, 321-330. doi:10.1016/i.ejcnurse.2004.05.002

[25] Fox, K.F., Nuttal, M., Wood, D.A., Wright, M., Arora, B., Dawson, E., et al. (2001) A cardiac prevention and rehabilitation programme for all patients at first presentation with coronary artery disease. Heart, 85, 533-538. doi:10.1136/heart.85.5.533

[26] Hansen, T., Nordrehaug, J., Eide, G. and Hanestad, B. (2007) Improving outcomes after myocardial infarction: A randomized controlled trial evaluating effects of a telephone follow-up intervention. European Journal of Cardiovascular Prevention and Rehabilitation, 14, 429437. doi:10.1097/HJR.0b013e32801da123

[27] Lear, S., Ignaszewski, A., Linden, W., Brozic, A., Kiess, M., Spinelli, J., et al. (2003) The Extensive Lifestyle Management Intervention (ELMI) following cardiac rehabilitation trial. European Heart Journal, 24, 1920-1927. doi:10.1016/j.ehj.2003.08.015

[28] Murchie, P., Campell, N., Ritchie, L., Simpson, J. and Thain, J. (2003) Secondary prevention clinics for coronary heart disease: Four-year follow-up of a randomised controlled trial in primary care. BMJ, 326, 84-89. doi:10.1136/bmj.326.7380.84

[29] Nordmann, A., Heilmbauer, I., Walker, T., Martina, B. and Battegay, E. (2001) A case-management program of medium intensity does not improve cardiovascular risk factor control in coronary artery disease patients: The heartcare I trial. American Journal of Medicine, 110, 543-550. doi:10.1016/S0002-9343(01)00682-9

[30] Mittag, O., China, C., Hoberg, E., Juers, E., Kolenda, K.D., Richard, G., et al. (2006) Outcomes of cardiac rehabilitation with versus without a follow-up intervention rendered by telephone (Luebeck follow-up trial): Overall and gender-specific effects. International Journal of Rehabilitation Research, 29, 295-302. doi:10.1097/MRR.0b013e328010ba9a

[31] Oldenburg, B., Martin, A., Greenwood, J., Bernstein, L. and Allan, R. (1995) A controlled trial of behavioral and educational intervention following coronary artery bypass surgery. Journal of Cardiopulmonary Rehabilitation, 15, 39-46. doi:10.1097/00008483-199501000-00006

[32] Wallner, S., Watzinger, N., Lindschinger, M., Smolle, K.H., Toplak, H., Eber, B., et al. (1999) Effects of intensified lifestyle modification on the need for further revascularization after coronary angioplasty. European Journal of Clinical Investigation, 29, 372-379. doi:10.1046/j.1365-2362.1999.00456.x

[33] The Vestfold Heartcare Study Group (2003) Influence on lifestyle measures and five-year coronary risk by comprehensive lifestyle intervention programme in patients with coronary heart disease. European Journal of Cardiovascular Prevention and Rehabilitation, 10, 429-437. doi:10.1097/01.hjr.0000107024.38316.6a

[34] Van Elderen, T. and Dusseldorp, E. (2001) Lifestyle effects of group health education for patients with coronary heart disease. Psychology and Health, 16, 327-341. doi: $10.1080 / 08870440108405510$

[35] Aldana, S.G., Whitmer, W.R., Greenlaw, R., Avins, A., Salberg, A., Barnhurst, M., et al. (2003) Cardiovascular risk reductions associated with aggressive lifestyle modification and cardiac rehabilitation. Heart \& Lung, 32, 374-382. doi:10.1016/S0147-9563(03)00106-7

[36] Carlsson, R., Lindberg, G., Westin, L. and Israelsson, B. (1997) Influence of coronary nursing management follow up on lifestyle after acute myocardial infarction. Heart, 44, 256-259. doi:10.1136/hrt.77.3.256

[37] Gordon, N., English, C., Contractor, A., Salmon, R., Leighton, R., Franklin, B. and Haskell, W. (2002) Effectiveness of three models for comprehensive cardiovascular disease risk reduction. American Journal of Cardiology, 89, 1263 1268. doi:10.1016/S0002-9149(02)02323-8

[38] Hofman-Bang, C., Lisspers, J., Nordlander, R., Nygren, Å., Sundin, Ö., Öhman, A., et al. (1999) Two-year results of a controlled study of residential rehabilitation for patients treated with percutaneos transluminal coronary angioplasty. European Heart Journal, 20, 1465-1474. doi:10.1053/euhj.1999.1544

[39] Lear, S., Spinelli, J., Linden, W., Brozic, A., Kiess, M., Frohlich, J., et al. (2006) The Extensive Lifestyle Managemnet Intervention (ELMI) after cardiac rehabilitation: A 4-year randomized controlled trial. American Heart Journal, 152, 333-339. doi:10.1016/j.ahj.2005.12.023

[40] Lisspers, J., Hofman-Bang, C., Nordlander, R., Rydén, L., Sundin, Ö., Öhman, A., et al. (1998) Multifactorial evaluation of a program for lifestyle behavior change in rehabilitation and secondary prevention of coronary artery disease. Scandinavian Cardiovascular Journal, 33, 9-16.

[41] Lisspers, J., Sundin, Ö., Hofman-Bang, C., Nordlander, R., Nygren, Å., Rydén, L., et al. (1999) Behavioral effects of a comprehensive multifactorial program for lifestyle change after percutaneous transluminal coronary angioplasty: A prospective, randomized, controlled study. Journal of Psychosomatic Research, 46, 143-154. doi:10.1016/S0022-3999(98)00074-9

[42] Lisspers, J., Sundin, O., Ohman, A., Hofman-Bang, C., Rydén, L. and Nygren, A. (2005) Long-term effects of lifestyle behaviour change in coronary artery disease: Effects on recurrent coronary events after percutaneous 
coronary intervention. Health Psychology, 24, 41-48. doi:10.1037/0278-6133.24.1.41

[43] Reid, R.D., Dafoe, W.A., Morrin, L., Mayhew, A., Papadakis, S., Beaton, L., et al. (2005) Impact of program duration and contact frequency on efficacy and cost of cardiac rehabilitation: Results of a randomized trial. American Heart Journal, 149, 862-868. doi:10.1016/j.ahj.2004.09.029

[44] Cobb, S., Brown, D. and Davies, L. (2006) Effective interventions for lifestyle change after myocardial infarction or coronary artery revascularisation. Journal of the American Academy of Nurse Practitioners, 18, 31-39. doi:10.1111/j.1745-7599.2006.00096.x

[45] Orth-Gomér, K. (2007) Psychosocial and behavioural aspects of cardiovascular disease prevention in men and woman. Current Opinion in Psychiatry, 20, 147-151.
doi:10.1097/YCO.0b013e32802b705e

[46] Orth-Gomér, K., Schneiderman, N., Wang, H., Walldin, C., Blom, M. and Jernberg, T. (2009) Stress reduction prolongs life in women with coronary disease: The Stockholm women's intervention trial for coronary heart disease (SWITCHD). Circulation: Cardiovascular Quality and Outcomes, 2, 25-32. doi:10.1161/CIRCOUTCOMES.108.812859

[47] Cooper, A.F., Jackson, G., Weinman, J. and Horne, R. (2002) Factors associated with cardiac rehabilitation attendance: A systematic review of the literature. Clinical Rehabilitation, 16, 541-552. doi:10.1191/0269215502cr524oa

[48] Polit, D.F. and Hungler, B.F. (2004) Nursing researchPrinciples and methods. 7th Edition, J.B. Lippincott Company, Philadelphia. 